\title{
Empowering school citizens in behavior clean and healthy life through school health business
}

\author{
Haflin Soraya Hutagalung $^{1 *}$, Sri Amelia ${ }^{2}$, Merina Panggabean ${ }^{3}$, Ariyati Yosi ${ }^{4,}$ Ridwan \\ Balatif $^{5}$ \\ ${ }^{1}$ Departemen Neurologi, Fakultas Kedokteran, Universitas Sumatera Utara \\ ${ }^{2}$ Departemen Mikrobiologi, Fakultas Kedokteran, Universitas Sumatera Utara \\ ${ }^{3}$ Departemen Parasitologi, Fakultas Kedokteran, Universitas Sumatera Utara \\ ${ }^{4}$ Departemen Ilmu Kesehatan Kulit dan Kelamin, Fakultas Kedokteran, \\ Universitas Sumatera Utara \\ ${ }^{5}$ Fakultas Kedokteran, Universitas Sumatera Utara \\ *Email: haflin.soraya@usu.ac.id
}

\begin{abstract}
One of the most problematic things faced by Indonesians is health issue, especially for school-age children. The cases which is occurred are behavioural disorder, the development of physiological disorder, learning disabilities, and general health problem, occur frequently in children. School Public Health is a place to promote Healthy and Clean Living Behaviour for school-age children. The community service team which consists of lecturer from Medical Faculty of Universitas Sumatera Utara do counseling and training activity in Susuk Village, Tiganderket sub-district, Karo disctrict. This activity was followed by 72 students, consisting of 18 students from grade 4, 33 students from grade 5, and 21 students from grade 6. Besides counseling and training activity, students was given a questionnaire form to measure their knowledge. From the answer of questionnaire, it was obtained that the respondent having good knowledge is 53 students $(73,6 \%), 23,6 \%$ having moderate knowledge, and 2,8\% having low knowledge.
\end{abstract}

Keywords: Training, conseling, School Public Health, Healthy and Clean Living Behaviour

\begin{abstract}
Abstrak
Salah satu permasalahan yang sering dihadapi Bangsa Indonesia adalah masalah kesehatan khususnya masalah kesehatan anak usia sekolah. Masalah yang timbul pada anak usia sekolah umumnya berupa gangguan perilaku, gangguan perkembangan fisiologis hingga gangguan dalam belajar dan juga masalah kesehatan umum. Usaha Kesehatan Sekolah (UKS) merupakan wadah untuk mengembangkan promosi Perilaku Hidup Bersih Sehat (PHBS) pada anak usia sekolah. Tim Pengabdian Masyarakat yang terdiri dari dosen Fakultas Kedokteran Universitas Sumatera Utara melakukan kegiatan penyuluhan dan pelatihan di Desa Susuk, Kecamatan Tiganderket, Kabupaten Karo. Kegiatan penyuluhan dan pelatihan diikuti sebanyak 72 siswa terdiri dari 18 orang kelas IV, 33 orang kelas V dan 21 orang kelas VI. Selain penyuluhan dan pelatihan, siswa juga diberikan kuesioner untuk mengukur tingkat pengetahuannya. Dari kuesioner didapatkan bahwa responden memiliki pengetahuan baik yakni sebanyak 53 orang $(73,6 \%), 23,6 \%$ berpengetahuan sedang dan $2,8 \%$ berpengetahuan kurang.
\end{abstract}

Kata kunci: Pelatihan, penyuluhan, Usaha Kesehatan Sekolah, Perilaku Hidup Bersih Sehat

\section{PENDAhULUAN}

Salah satu permasalahan serius yang dihadapi Bangsa Indonesia adalah masalah kesehatan anak usia sekolah. Populasi anak usia sekolah dasar merupakan komponen yang cukup penting dalam 
masyarakat, mengingat jumlah populasi mereka yang besar yakni berkisar 25.486 .506 orang atau sekitar 10\% dari jumlah penduduk Indonesia pada tahun 2017 (Kemdikbud, 2017). Masalah yang sering timbul pada anak usia sekolah umumnya berupa gangguan perilaku, gangguan perkembangan fisiologis hingga gangguan dalam belajar dan juga masalah kesehatan umum. Problema ini berkaitan dengan kebersihan perseorangan dan lingkungan.

Keputusan Menteri Kesehatan Nomor 1193/Menkes/SK/ X/2004 tentang Visi Promosi Kesehatan RI adalah "Perilaku Hidup Bersih Sehat 2010" atau "PHBS 2010" menjadi salah satu upaya pemerintah dalam mengatasi masalah kebersihan. Perilaku Hidup Bersih Sehat (PHBS) di sekolah adalah perilaku-perilaku yang dilaksanakan oleh peserta didik, guru, dan masyarakat lingkungan sekolah atas dasar kesadaran sebagai hasil pembelajaran, sehingga secara mandiri mampu mencegah penyakit, meningkatkan kesehatan serta berperan aktif dalam menciptakan lingkungan yang sehat (Sulastri, Purna, dan Suyasa, 2014). Usaha Kesehatan Sekolah (UKS) menjadi salah satu wadah untuk mengembangkan promosi PHBS pada anak usia sekolah. Tujuan umum UKS adalah untuk meningkatkan kemampuan hidup sehat dan derajat kesehatan peserta didik serta menciptakan lingkungan yang sehat, yang memungkinkan pertumbuhan yang harmonis dan optimal dalam rangka pembentukan manusia Indonesia yang seutuhnya (Entjang, 1983).

UKS menjadi wadah utama pendidikan kesehatan yang ada di sekolah untuk meningkatkan kemampuan hidup sehat dan selanjutnya membentuk perilaku hidup sehat. Dalam mencapai derajat kesehatan yang setinggi-tingginya peserta didik diberi kesempatan untuk tumbuh dan berkembang sebaik-baiknya dengan menyediakan lingkungan yang sebaik-baiknya pula. Oleh karena itu peranan masyarakat sekolah yang terdiri atas guru, murid, serta orang tua murid menjadi utama dan diharapkan dengan adanya UKS bukan masyarakat sekolah saja yang menjalankan hidup sehat, tetapi masyarakat sekitar juga akan menjalankan hidup sehat dalam kesehariannya. UKS mempunyai program yang dilaksanakan di sekolah yang dikenal dengan sebutan TRIAS UKS yang terbagi menjadi tiga bidang pokok yaitu Pendidikan Kesehatan, Pelayanan Kesehatan dan Pembinaan Lingkungan Kehidupan Sekolah Sehat.

Dengan adanya program TRIAS UKS di sekolah terutama di sekolah dasar diharapkan dapat dilaksanakan dengan maksimal agar kondisi dan terjaganya kesehatan seluruh lingkungan sekolah baik sehat secara fisik, mental dan sosial. Oleh karena itu, dalam upaya untuk menciptakan lingkungan sekolah yang bersih dan sehat - dimulai dari PHBS, tim pengusul memerlukan keterlibatan kepala sekolah, para guru dan para siswa dalam seluruh rangkaian penyuluhan. Berdasarkan Kegiatan Pengabdian Masyarakat Mandiri yang dilaksanakan pada tanggal 21 Maret 2019 yang lalu, diketahui bahwa SDN 040494 Desa Susuk, Kecamatan Tiganderket, Kabupaten Karo belum melaksanakan program pelaksanaan UKS secara optimal. Hal ini terjadi karena sarana prasarana UKS yang masih terbatas dan kurangnya kerjasama yang baik dengan pihak-pihak terkait.

\section{METODE PELAKSANAAN}

Kegiatan pengabdian masyarakat ini dilaksanakan oleh tim Pengabdian Masyarakat yang terdiri dari dosen Fakultas Kedokteran Universitas Sumatera Utara kepada siswa kelas IV hingga VI SDN 040494 Desa Susuk, Kecamatan Tiganderket, Kabupaten Karo. Kegiatan yang dilaksanakan dibagi menjadi dua tahap yaitu penyuluhan, pelatihan kesehatan dan diseminasi. Pada tahap awal, tim pengabdian kepada masyarakat melakukan penyuluhan kesehatan dibantu oleh mahasiswa FK USU. Kegiatan ini terintegrasi dengan mata pelajaran Pendidikan Jasmani yang sudah dimulai dari kelas 1 sekolah dasar. Siswa kelas 4, 5 dan 6, selain dikenalkan PHBS juga diajarkan cara mencuci tangan dan pemilihan makanan sehat. Di akhir kegiatan, akan diumumkan dokter kecil yang akan bertugas selama satu tahun ke depan. Materi yang diberikan berupa PHBS dan pemilihan makanan sehat. Selanjutnya dilaksanakan pelatihan yang ditujukan sebagai upaya pertolongan pertama pada 
masalah kesehatan yang timbul. Kegiatan ini bertujuan untuk melatih siswa agar dapat melaksanakan sebagian upaya pemeliharaan dan peningkatan kesehatan terhadap diri sendiri, teman, keluarga dan lingkungannya. Di akhir kegiatan pada masyarakat, dlaksanakan pemilihan dokter kecil dimana peserta kegiatan adalah siswa kelas 4, 5 dan 6 yang telah menerima penyuluhan dan pelatihan sebelumnya.

\section{HASIL DAN PEMBAHASAN}

Target pendidikan dan pelayanan kesehatan yang ditujukan pada kelompok tertentu akan menentukan keberhasilan suatu program kesehatan. Pemilihan anak usia sekolah disebabkan karena jumlahnya mencapai 30\% dari jumlah penduduk Indonesia (Depkes, 2008). Pendidikan dan pelayanan kesehatan yang diberikan sejak dini akan lebih baik hasilnya dibandingkan bila diberikan pada usia yang lebih tinggi, mengingat pada usia dini relatif belum terbentuk sikap dan perilakunya sehingga akan lebih mudah menanamkan perilaku hidup bersih dan sehat dibandingkan dewasa (Wulandari, 2011). Program Dokter Kecil pada hakekatnya adalah diambil dari siswa yang memenuhi kriteria dan telah dilatih untuk ikut melaksanakan sebagai usaha pemeliharaan dan peningkatan kesehatan terhadap diri sendiri, teman, keluarga dan lingkungannya.

Program Dokter Kecil telah termuat dalam program TRIAS UKS pada kegiatan pelayanan kesehatan. Berdasarkan hasil pengamatan dan wawancara dengan kepala sekolah pada saat Sosialisasi, diketahui bahwa terkendalanya pelaksanaan Program Usaha Dokter Kecil dalam UKS disebabkan rendahnya kesadaran dalam melaksanakan program yang menjadi dasar penyelenggaraan kegiatan tersebut serta minimnya sarana dan prasarana yang mendukung pelaksanaan UKS yang kurang maksimal. Mengacu pada Pedoman Pelatihan Dokter Kecil yang dikeluarkan Direktorat Bina Kesehatan Anak pada tahun 2013, kriteria mengikuti pelatihan Dokter Kecil antara lain adalah telah menduduki kelas 4SD/MI dan atau siswa kelas 5 dan 6 yang belum pernah mendapatkan pelatihan "Dokter Kecil". Sebanyak 72 siswa mengikuti kegiatan penyuluhan dan pelatihan yang terdiri dari siswa kelas IV, V dan VI. Berikut data demografi berdasarkan kelas

Tabel 3.1. Data demografi siswa

\begin{tabular}{|c|c|c|c|c|}
\hline \multirow[t]{2}{*}{ Kelas } & \multicolumn{2}{|c|}{ Laki-laki } & \multicolumn{2}{|c|}{ Perempuan } \\
\hline & $\mathrm{n}$ & $\%$ & $\mathrm{n}$ & $\%$ \\
\hline IV & \multicolumn{4}{|c|}{18 orang } \\
\hline Jenis kelamin & 10 & 55,5 & 8 & 44,5 \\
\hline Usia & \multicolumn{2}{|c|}{9,4 tahun } & \multicolumn{2}{|c|}{9,5 tahun } \\
\hline V & \multicolumn{4}{|c|}{33 orang } \\
\hline Jenis kelamin & 20 & 60,6 & 13 & 39,4 \\
\hline Usia & \multicolumn{2}{|c|}{10,3 tahun } & \multicolumn{2}{|c|}{10,7 tahun } \\
\hline VI & \multicolumn{4}{|c|}{21 orang } \\
\hline Jenis kelamin & 9 & 42,9 & 12 & 57,1 \\
\hline Usia & \multicolumn{2}{|c|}{11,8 tahun } & \multicolumn{2}{|c|}{11 tahun } \\
\hline
\end{tabular}

Menurut Departemen Pendidikan Nasional pada tahun 2011, tugas dan kewajiban dokter kecil yaitu selalu bersikap dan berperilaku sehat sehingga dapat menjadi contoh bagi temantemannya, dapat menggerakkan sesama siswa untuk bersama-sama menjalankan usaha kesehatan terhadap dirinya masing-masing, berusaha bagi tercapainya kesehatan lingkungan yang baik di sekolah dan di rumah, membantu guru dan petugas kesehatan pada waktu pelaksanaan pelayanan kesehatan di sekolah, berperan aktif pada kegiatan dalam rangka upaya peningkatan kesehatan di sekolah. Oleh karena itu, tim Pengabdian kepada Masyarakat melakukan penyuluhan tentang pelayanan kesehatan di sekolah termasuk pengenalan diri tanda-tanda penyakit. Selain itu juga 
memberikan penyuluhan materi PHBS, pencegahan kecacingan, pola makan yang sehat serta pertolongan pertama pada penyakit dan kecelakaan.

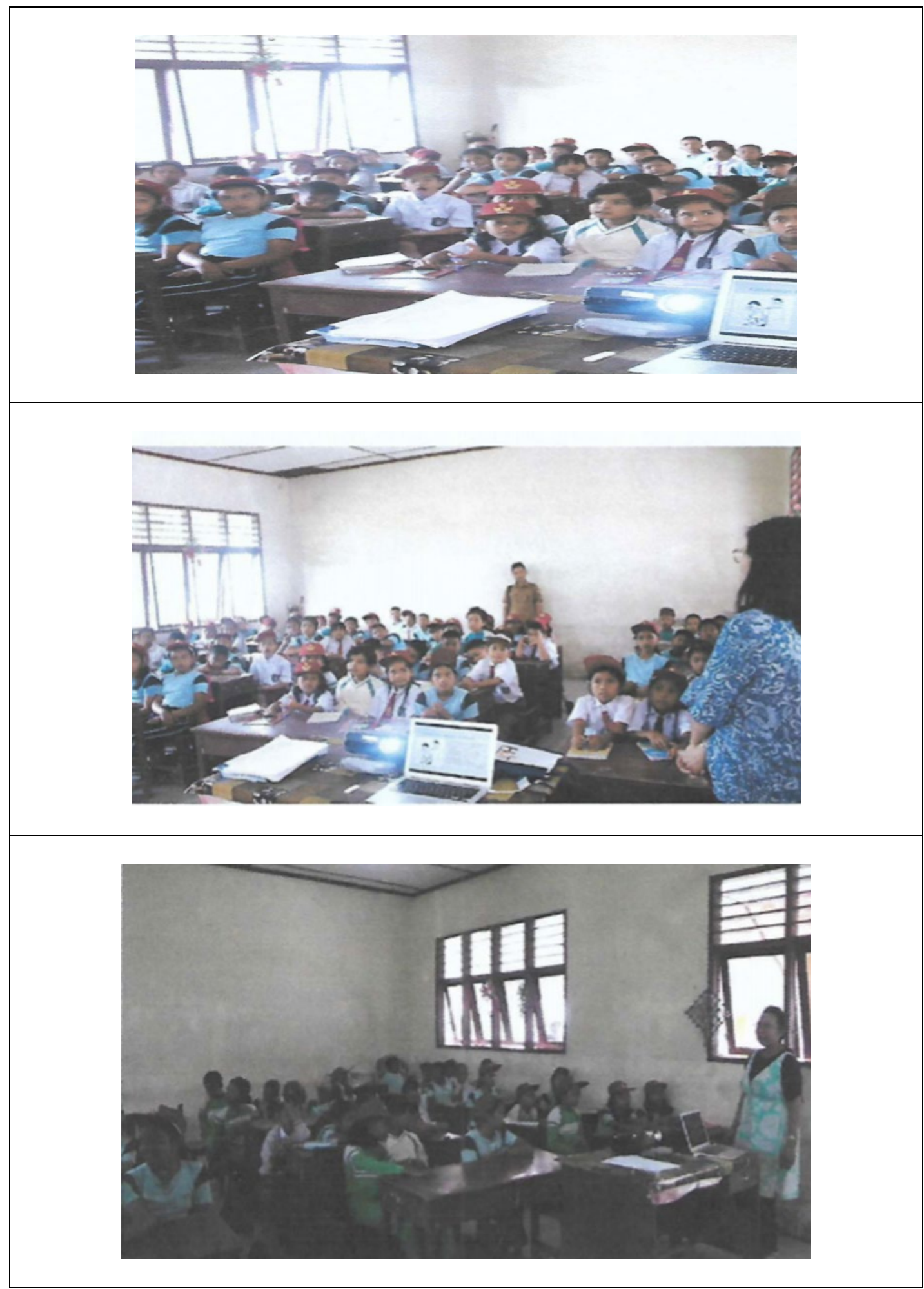

Gambar 3.1. Kegiatan penyuluhan 


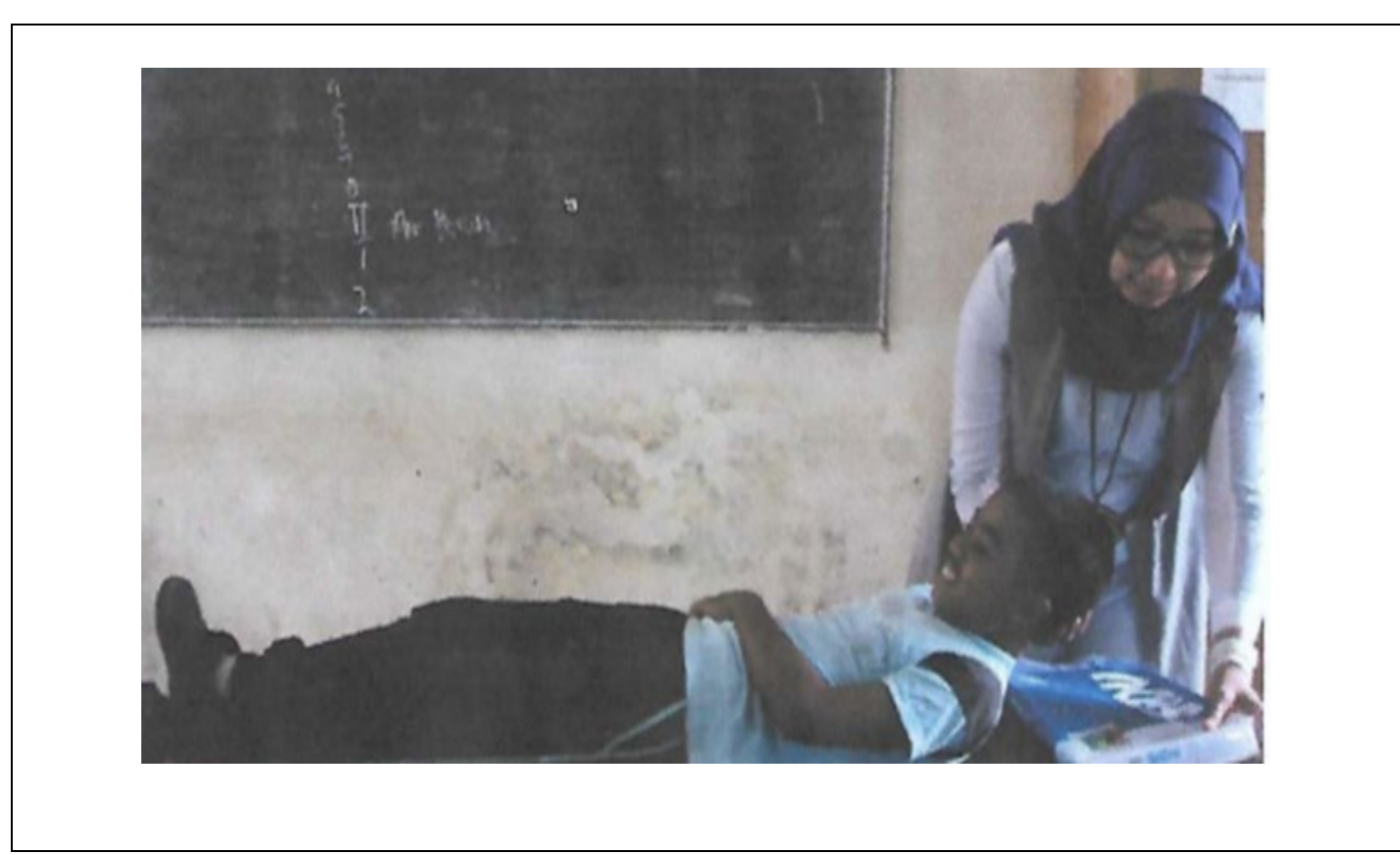

Gambar 3.2. Penyuluhan

Jika ditinjau dari segi pengetahuan, sebagian besar responden memiliki tingkat pengetahuan yang baik yakni 53 orang $(73,6 \%)$ dan sisanya berpengetahuan sedang dan hanya $2,8 \%$ berpengetahuan kurang. Meskipun sebagian besar responden berpengetahuan baik, tetapi pada soalan penanganan sampah mayoritas responden tidak mengetahui dengan baik.

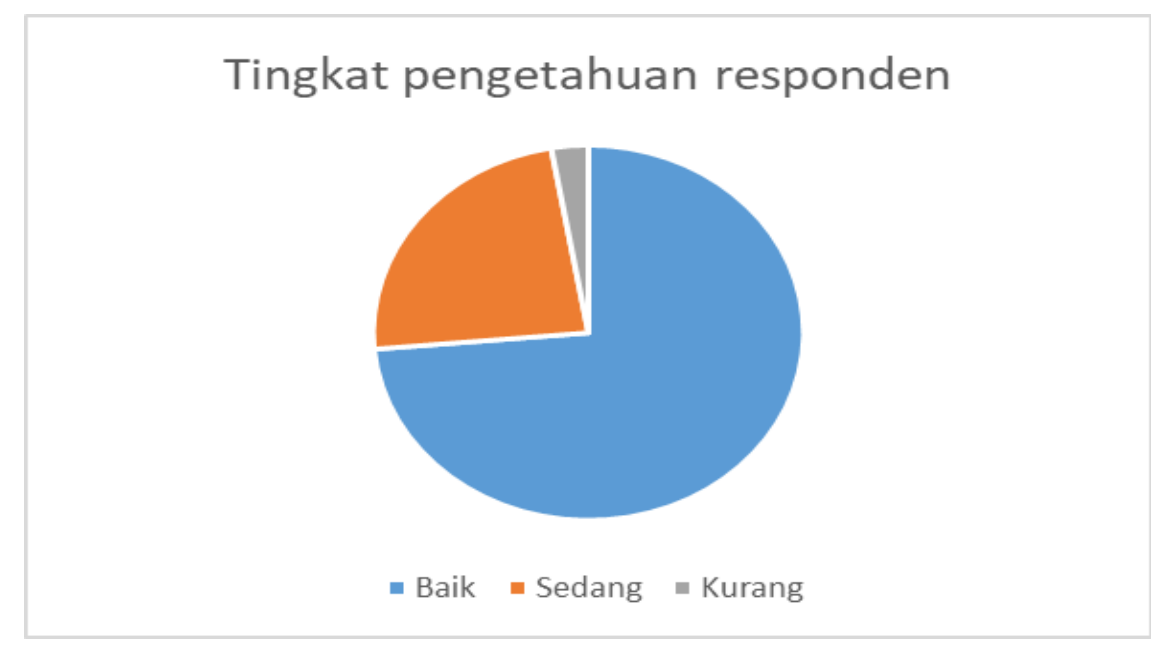

Gambar 3.3. Tingkat pengetahuan responden tentang materi penyuluhan

Pada kesempatan yang sama, tim pengabdian masyarakat memberikan bantuan peralatan UKS untuk membantu kegiatan dokter kecil di SDN 040494 Susuk, Kecamatan Tiganderket. 


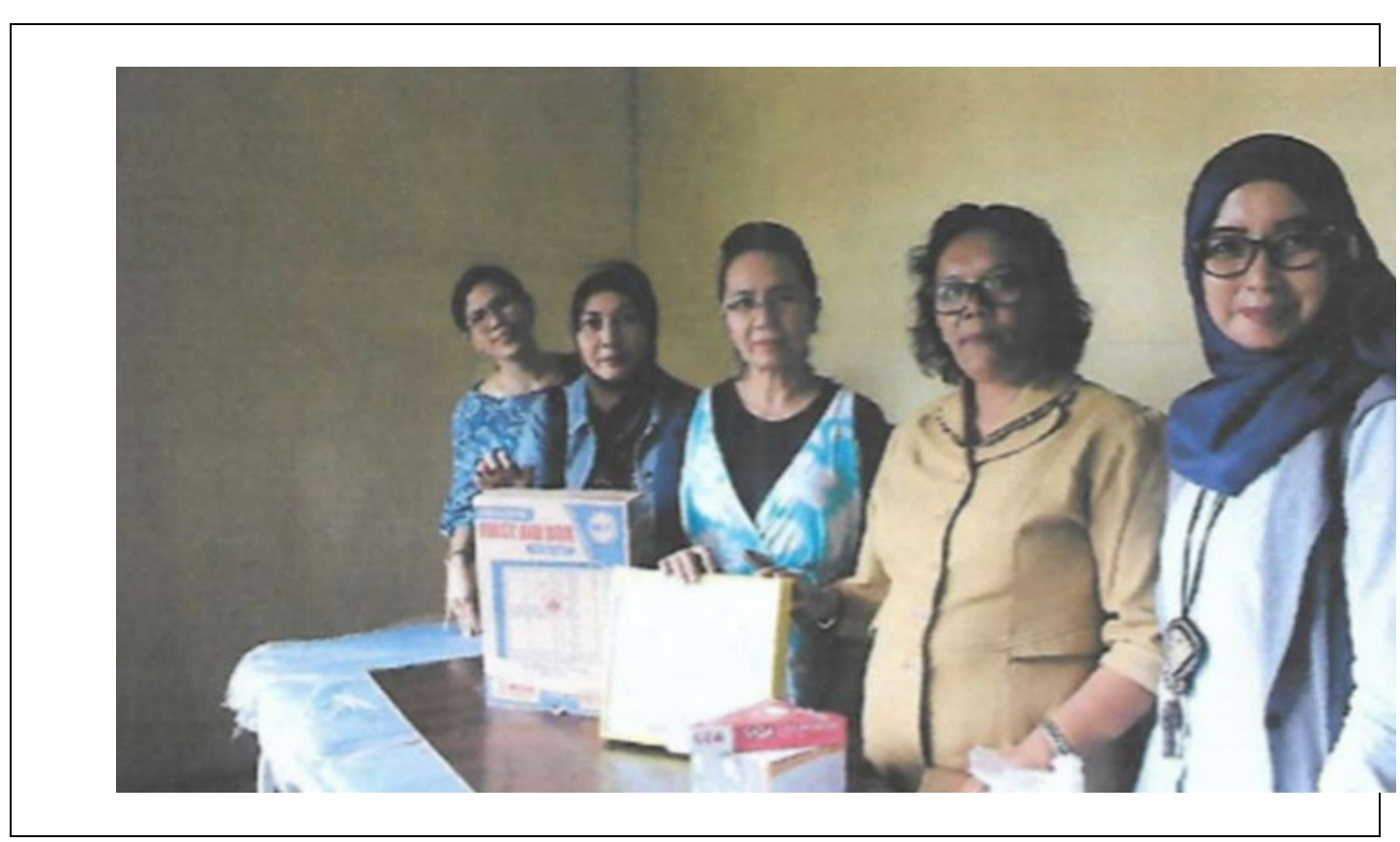

Gambar 3.4. Penyerahan bantuan

\section{KESIMPULAN}

Jumlah responden mulai kelas IV hingga VI SDN 040494 Susuk, Kecamatan Tiganderket yang mengikuti rangkaian kegiatan penyuluhan dan pelatihan dokter kecil berjumlah 72 orang dengan 39 orang berjenis kelamin laki-laki dan 33 orang berjenis kelamin perempuan serta rata-rata usia 10,5 tahun. Rata-rata tingkat pengetahuan responden tergolong baik. Dalam rangka peningkatan kemandirian dan kemampuan siswa Sekolah Dasar dalam mempertahankan derajat kesehatan baik dirinya pribadi, keluarga dan masyarakat sekitar perlu diupayakan sinergitas antara para pemangku kepentingan seperti akademisi, aparat pemerintahan, tenaga kesehatan.

\section{UCAPAN TERIMA KASIH}

Artikel ini merupakan salah satu hasil dari Program Pengabdian kepada Masyarakat yang dibiayai oleh Lembaga Pengabdian Kepada Msyarakat Universitas Sumatera Utara tahun 2019 Skema Dosen Mengabdi. Oleh karena itu, diucapkan terima kasih kepada Rektor Universitas Sumatera Utara atas dukungan dana dan fasilitas yang diberikan. Terima kasih juga kepada Mitra pada kegiatan pengabdian ini.

Artikel ini merupakan salah satu hasil dari Program Pengabdian kepada Masyarakat Sumber Dana Non PNPB Universitas Sumatera Utara Sesuai dengan Surat Perjanjian Penugasan Pelaksanaan Program Pengabdian kepada Masyarakat Skim Dosen Mengabdi Tahun Anggaran 2019 Nomor: 785/ UN5.2.3.2.1/ PPM /2019, Tanggal 23 Juli 2019.

\section{DAFTAR PUSTAKA}

Entjang, I. 1983. Kesehatan Masyarakat. Jakarta: PT Citra Aditya Bakti

Kementerian Pendidikan dan Kebudayaan. Pusat Data dan Statistik Pendidikan 2017/2018. Available from: http://statistik.data.kemdikbud.go.id/ 
Mikail, Bramirus. 2011. Anak Sekolah, Agen Perubahan Pola Hidup: Sehat

Prastianingsih Y. Perbedaan tingkat perilaku hidup bersih dan sehat (PHBS) di Sekolah Dasar dan Sekolah Dasar Swasta di Kecamatan Kenjeran. Surabaya: Universitas Muhammadiyah

Promosi Kesehatan Di Sekolah. Pusat Promosi Kesehatan Departemen Kesehatan Republik Indonesia 2007.

Sulastri, K., Purna, I, N., Suyasa, I, N, G. (2014). Hubungan Tingkat Pengetahuan Dengan Perilaku Anak Sekolah Tentang Hidup Bersih dan Sehat di Sekolah Dasar Negeri Wilayah Puskesmas Selemadeg Timur II. Jurnal Kesehatan Lingkungan 4(1); 99-106.

Wulandari, H. Pelaksanaan Pendidikan Kesehatan Perilaku Hidup Bersih dan Sehat (PHBS) Pada Anak Usia Dini di TK Aba Tegalsari Yogyaakarta. Tesis, Universitas Islam Negeri Sunan Kalijaga, Yogyakarta 